\title{
Evaluating models of the topographical organization of working memory function in frontal cortex with event-related fMRI
}

\author{
BRADLEY R. POSTLE \\ University of Wisconsin, Madison, Wisconsin \\ and \\ MARK D'ESPOSITO \\ University of Califormia, Berkeley, California
}

\begin{abstract}
Many influential claims about the organization of working memory function in prefrontal cortex (PFC) have been developed and/or tested with functional neuroimaging methods featuring the blocking of behavioral trials and the averaging across blocks of neuroimaging signal. Interpretation of the results of these first-generation neuroimaging studies is subject to several inferential constraints that thereby weaken the models derived from them. We reassessed several models of the functional organization of working memory in PFC by examining or reanalyzing data that were not subject to the same inferential constraints from three event-related fMRI studies of working memory function performed in our laboratory (D'Esposito, Postle, Ballard, \& Lease, 1999; Postle, Berger, \& D'Esposito, 1999; Postle \& D'Esposito, 1999). This process permitted us to reject some of the models derived from firstgeneration neuroimaging data, to refine others, and to synthesize our results into a revised hybrid model of the working memory functions of PFC.
\end{abstract}

Prominent among the thousands of publications that, beginning in the mid-1980s, represent this nascent period in the history of cognitive neuroscience have been neuroimaging studies of the working memory functions of the prefrontal cortex (PFC). The results of these studies have been an important source of data from which current models of the organization of mnemonic functions of PFC have been constructed. The models that we will consider in this paper can be classified into two broad categories - those that emphasize organization by stimulus domain and those that emphasize organization by process - and are summarized in Table 1. The influence of these models extends beyond the study of working memory (Wagner, 1999).

Many of these models are archetypal exemplars of cognitive neuroscience in that they have their roots in electrophysiological and lesion studies of monkeys. The organization-by-stimulus-domain models, for example, were motivated by Goldman-Rakic's (1987) modular organizational scheme for PFC, with anatomically discrete

This work was supported by the American Federation for Aging Research and National Institutes of Health Grants NS01762 and AG13483. B.R.P. also received support from National Institutes of Health Grant AG00255 (to Virginia M.-Y. Lee, University of Pennsylvania Medical Center). We thank Jeffrey S. Berger for assistance with analyses and figure production. Correspondence should be addressed to B. R. Posthe, Department of Psychology, University of Wisconsin, 1202 W. Johnson St., Madison, WI 53706-1696 (e-mail: postle@facstaff.wisc.edu). regions of PFC supporting working memory processing in a fashion that preserves the segregation of domainspecific sensory processing areas. Particularly influential has been the proposal that PFC visual working memory processing for spatial and object characteristics of stimuli segregated in a fashion reflecting the dorsal/ventral segregation of the visual system (Wilson, O'Scalaidhe, \& Goldman-Rakic, 1993). Organization-by-process models, in contrast, were preceded by Petrides's proposal that working memory functions of lateral PFC are organized into two stages, with ventrolateral areas $12 / 47$ and 45 supporting computationally simpler executive functions such as the active comparison and assessment of stimuli represented in working memory, and mid-dorsolateral areas 9 and 46 supporting the computationally more complex functions of monitoring actions in the recent past and/or the number of stimuli represented in working memory and their relevance for behavioral objectives (Petrides, 1994).

Because many models of the organization of working memory function in human frontal cortex derive so directly from work in the monkey, it is helpful to keep in mind the assumptions of anatomical homology between the monkey and the human that these studies make, either implicitly or explicitly. It is widely assumed by neuroimagers that the principal sulcus in the monkey, which divides the lateral PFC into dorsal and ventral regions, is homologous to the inferior frontal sulcus in humans. Thus, middle frontal gyrus (comprising Brodmann's areas 9 and 46) that is dorsal to this sulcus would be proposed to be specialized for spatial working memory in certain 
Table 1

Summary of the Models of the Topographical Organization of Working Memory Function in Prefrontal Cortex (PFC) Assessed in This Report

\begin{tabular}{|c|c|}
\hline Label & Model \\
\hline \multicolumn{2}{|r|}{ Organization-by-Domain } \\
\hline A & $\begin{array}{l}\text { Dorsolateral and ventrolateral regions of frontal cortex may } \\
\text { differentially support working memory for spatial and ob- } \\
\text { ject stimuli, respectively (Courtney, Ungerleider, Keil, \& } \\
\text { Haxby, 1996; Smith \& Jonides, 1999; Smith et al.. 1995) }\end{array}$ \\
\hline $\mathrm{B}$ & $\begin{array}{l}\text { Left and right mid-dorsolateral PFC may differentially sup- } \\
\text { port working memory for spatial and object stimuli, respec- } \\
\text { tively (Baker, Frith, Frackowiak, \& Dolan, 1996; Belger } \\
\text { et al., 1998; McCarthy et al., 1996) }\end{array}$ \\
\hline $\mathrm{C}$ & $\begin{array}{l}\text { Left and right ventrolateral PFC may differentially support } \\
\text { working memory for spatial and object stimuli, respectively } \\
\text { (D'Esposito, Aguirre, Zarahn, \& Ballard, 1998; Smith et al., } \\
\text { 1995) }\end{array}$ \\
\hline $\mathrm{D}$ & $\begin{array}{l}\text { Working memory for verbal material may be preferentially } \\
\text { processed in the left hemisphere of PFC (Awh et al., 1996; } \\
\text { Gabrieli, Poldrack, \& Desmond, 1998; Smith \& Jonides, } \\
\text { 1999; Smith, Jonides, Marshuetz, \& Koeppe, 1998) }\end{array}$ \\
\hline \multicolumn{2}{|r|}{ Organization-by-Process } \\
\hline $\mathrm{E}$ & $\begin{array}{l}\text { Dorsolateral PFC may be recruited preferentially to support } \\
\text { manipulation of items held in working memory (D'Espos- } \\
\text { ito et al., 1998; Owen, Evans, \& Petrides, 1996; Owen et al., } \\
\text { 1999) }\end{array}$ \\
\hline $\mathrm{F}$ & $\begin{array}{l}\text { An extension of Model E: Dorso- and ventrolateral PFC } \\
\text { may, to the relative exclusion of other processes, support } \\
\text { manipulation and maintenance, respectively, of items held } \\
\text { in working memory (i.e., a double dissociation in which dor- } \\
\text { solateral PFC preferentially supports manipulation pro- } \\
\text { cesses and ventrolateral PFC preferentially supports main- } \\
\text { tenance processes; Owen et al., 1999; Smith \& Jonides, } \\
\text { 1999; Smith et al., 1998) }\end{array}$ \\
\hline
\end{tabular}

organization-by-domain models, or for the manipulation of items in working memory in certain organization-byprocess models, whereas the inferior frontal gyrus (comprising Brodmann's areas 44, 45, and 47) that is ventral to this sulcus would be proposed to be specialized for nonspatial working memory, or for the maintenance of items in working memory, respectively.

The neuroimaging studies listed in Table 1 can be viewed as belonging to the first generation of neuroimaging methods - the positron emission tomography (PET) and functional magnetic resonance imaging (fMRI) studies that have employed a method developed in the mid-1980s characterized by the blocking of behavioral trials that belong to the same level of an experimental factor, and the averaging across tens of seconds of task performance to extract a single number that reflects the average level of neuroimaging signal during that tens-of-seconds-long block (Fox et al., 1986; Fox, Mintun, Reiman, \& Raichle, 1988; Posner, Petersen, Fox, \& Raichle, 1988). Interpretation of data acquired with these methods, however, must be tempered by several inferential constraints that accompany the methods with which block-design data are typically processed and analyzed. Noteworthy among these methods are (1) the averaging of neuroimaging signal across a block of trials; (2) the "cognitive subtraction" of signal from two matched blocks of trials; (3) the spatial smoothing of data; (4) the spatial normalization of data; and (5) the use of fixed effects models in group analyses. The accompanying inferential constraints include, respectively, (1) the inability to isolate neuroimaging signal ascribable to theoretically dissociable mental processes (Zarahn, Aguirre, \& D'Esposito, 1997b); (2) the unreliability of the assumption of pure insertion upon which many cognitive subtraction designs depend (Friston et al., 1996; Zarahn et al., 1997b, 1999); (3) the loss of spatial resolution due to smoothing; (4) the implicit assumption behind the spatial normalization of data of precise topographical correspondence of functional specialization across participants (Postle, Zarahn, \& D'Esposito, 2000); and (5) the inability to generalize the results of analyses employing fixedeffects models beyond the individual participants constituting the sample (Friston, Holmes, \& Worsley, 1999; Woods, 1996).

Thus, the conclusions drawn from a first-generation neuroimaging study of, say, performance on the n-back working memory task, may be limited because of the inability to resolve the discrete contributions to neuroimaging signal of the mnemonic processes of storage and maintenance of items in working memory from the nonmnemonic control processes of shifting attention, mediating proactive interference, and coordinating multipletask performance. Furthermore, in some cases the conclusions drawn from first-generation neuroimaging studies may be inaccurate due to failures of cognitive subtraction. Work in our laboratory, for example, has demonstrated that PFC voxels that do not demonstrate delay-period activity in a delayed-recognition task can show significantly greater response-related activity in a yes/no recognition task when the response is preceded by a delay period than when it is not (Zarahn et al., 1997b, 1999). This type of voxel would be interpreted incorrectly as a voxel demonstrating delay-period activity in a block design task analyzed under the logic of cognitive subtraction.

The recent development of event-related fMRI techniques (e.g., Buckner et al., 1996; Josephs, Turner, \& Friston, 1997; Richter, Ugurbil, Georgopoulos, \& Kim, 1997; Zarahn et al., 1997b) has provided a second generation of neuroimaging methods to which the shortcomings that characterize the first generation of PET and FMRI methods do not apply, and with which the models of PFC working memory functions can be profitably reassessed. Since the development in our laboratory of an event-related fMRI method designed to permit direct assessment of delayperiod activity in delayed-recognition tasks (Zarahn et al., 1997b), we have performed several studies designed to test hypotheses about the organization of working memory function in PFC. The delayed-recognition task that typifies many of our studies features (1) the presentation of one or more target stimuli at the beginning of the trial, followed by (2) a delay period of several seconds, followed by (3) the presentation of a probe stimulus that assesses memory for the target(s). Because our event-related fMRI design and analysis method permits assessment of the variance in the fMRI signal attributable to 
each of these components of the delayed-recognition trial, uncontaminated by variance attributable to the other trial components, ${ }^{1}$ the data generated by our studies can be reanalyzed to address many of the models of the functional organization of working memory in frontal cortex that are summarized in Table 1. Although the exercise that follows will reflect, in many instances, a post hoc reanalysis of data from experiments not originally designed to address the questions posed here, the conclusions that we draw from it can serve as preliminary reassessments of models first motivated by data from first-generation neuroimaging studies. In cases where we have designed experiments explicitly to test hypotheses embodied by these models, we will summarize briefly the relevant results and conclusions. Because we are limiting ourselves in this report to the assessment of models derived from (first-generation) neuroimaging data with the reanalysis of (second-generation) neuroimaging datasets, caveats about the inferential limitations of neuroimaging data apply (D'Esposito \& Postle, 1999; Sarter, Berntson, \& Cacioppo, 1996).

\section{METHOD}

\section{Participants}

Participants in each of our studies were healthy, unmedicated young adults recruited from the University of Pennsylvania undergraduate and medical campuses; all provided informed consent. Six participants performed a spatial/object delayed-recognition task (Postle \& D'Esposito, 1999), and two separate studies of delayed recognition with letter stimuli featured 7 (D'Esposito, Postle, Ballard, \& Lease, 1999) and 5 (Postle, Berger, \& D'Esposito, 1999) participants, respectively.

\section{Behavioral Tasks}

Spatial/object delayed recognition. Each trial in the spatial/object delayed-recognition task (Postle \& D'Esposito, 1999) (Figure 1A) lasted $17 \mathrm{sec}$, beginning with an instructional cue $(500 \mathrm{msec})$, followed by an initial target stimulus presentation ( $1 \mathrm{sec}$ ), followed by a delay period (Delay $1 ; 6.5 \mathrm{sec}$ ), followed by the presentation of the initial target (match) stimulus and a foil stimulus (intermediate stimulus presentation; $1.5 \mathrm{sec}$ ), followed by a second delay period (Delay $2 ; 6.5 \mathrm{sec}$ ), followed by a probe stimulus (final probe; $1 \mathrm{sec}$ ). An intertrial interval (ITI) of $15 \mathrm{sec}$ separated each trial; the time from trial onset to trial onset was $32 \mathrm{sec}$. A fixation cross appeared with the onset of the initial target and remained on the screen until the offset of the final probe. The instructional cue read "shape first" or "location first" in a pseudorandomly determined order. In shapefirst, or what-then-where, trials, participants were trained to encode the featural details of the initial target, ignoring its location on the screen, and to retain this featural information during Delay 1 . The two intermediate stimuli both appeared in a location different from that occupied by the initial target, and their onset prompted a discrimination as to which of the two was an identical featural match with the initial target. Immediately upon making this discrimination, participants encoded the location of the match stimulus and retained this location information during Delay 2. Upon presentation of the final probe, participants judged whether or not it occupied the same location as the location target stimulus (i.e., as the match stimulus from the intermediate stimulus presentation) and indicated their decision with a "yes" or "no" buttonpress (right or left thumb, respectively). In location-first, or where-then-what, trials, one of the two intermediate stimuli, the match stimulus, occupied the same location as the initial target and the nonmatching stimulus occupied an adjacent location, and the final probe always appeared in a location different from the locations occupied by the intermediate stimuli. Participants were trained to perform spatial delayed recognition during the first half of the trial, to encode featural information about the location-match probe from the intermediate stimulus presentation, and to perform object delayed recognition during the second half of the trial. Posttest debriefing of participants, as well as the pattern of fMRI results (Postle \& D'Esposito, 1999), indicated that participants did not employ a strategy of maintaining information about both visual dimensions of stimuli across both delays of the trial. This what-then-where design was modified from that of Rao, Rainer, and Miller (1997).

Letter delayed item recognition. Each trial of the letter delayed item recognition task (D'Esposito, Postle, Ballard, \& Lease, 1999; Postle et al., 1999) (Figures 1B and 1C) lasted $14 \mathrm{sec}$, presenting sequentially the memory set $(2.5 \mathrm{sec})$, initial delay $(1 \mathrm{sec})$, instructions ("Forward" or "Alphabetize"; $500 \mathrm{msec})$, principal delay $(8 \mathrm{sec})$, and a letter-digit probe ( $1 \mathrm{sec})$. The ITI was $16 \mathrm{sec}$. The memory set for each trial type consisted of five randomly selected and randomly ordered consonant letters. (In the Postle et al., 1999, study one half of the Forward trials featured memory sets of two items, thereby introducing a memory load factor.) For 2 participants in D'Esposito, Postle, Ballard, and Lease (1999) and for all 5 participants in Postle et al. (1999), the probe always contained a letter from the memory set, and the digit represented with $p=.5$ the correct position of that letter in the memory set (thus assessing memory for item position on Forward trials, and for relative position in the alphabet of an item on Alphabetize trials). For the remaining 5 participants in D'Esposito, Postle, Ballard, \& Lease (1999), the probe on Forward trials consisted of a letter that represented with $p=.5$ one of the items from the memory set (thus assessing memory for item identity; no digit was presented). Participants responded to both probe types with buttonpresses analogous to those required in the spatial/object delayed-recognition task.

\section{fMRI Procedure}

Data for each of our event-related fMRI experiments were acquired on a 1.5 Tesla SIGNA scanner (GE Medical Systems) equipped with a prototype fast gradient system for echo-planar imaging. A standard radiofrequency (RF) head coil was used. Foam padding restricted head motion comfortably. The first scan of each of our event-related fMRI experiments was to derive empirically an estimate of the hemodynamic response function (HRF) for each participant. Once derived, the HRF, which characterizes the fMRI response resulting from a brief impulse of neural activity (Boynton, Engel, Glover, \& Heeger, 1996), would be used to smooth independent variables in our regression model. During the HRF derivation scan each participant performed a simple reaction time task that required a bimanual buttonpress once every $16 \mathrm{sec}$ in response to a change in shape of a fixation stimulus (for some HRF scans the in terstimulus interval [ISI] was $20 \mathrm{sec}$; see Aguirre, Zarahn, \& D'Esposito, 1998, for details).

Postprocessing of all fMRI data was performed on Sun Ultra workstations with analysis routines developed in our laboratory that featured programs written in Interactive Data Language (IDL) and C. Significance of buttonpress-correlated activity in each voxel of a primary somatosensory and motor cortical region of interest (ROI) was evaluated with a partial $F$ test associated with a Fourier basis covariate set (Josephs et al., 1997). An HRF estimate was extracted from the suprathreshold voxels of the ROI by spatially averaging their time series, filtering the resultant averaged $f M R I$ time series to remove high $(>0.244 \mathrm{~Hz})$ and low $(<0.05 \mathrm{~Hz})$ frequencies, adjusting it to remove the effects of nuisance covariates (Friston, Holmes, Poline, Heather, \& Frackowiak, 1995), and trial averaging.

Our inferential statistics were derived using multiple regression. We modeled the BOLD signal changes occurring during each qual- 
A
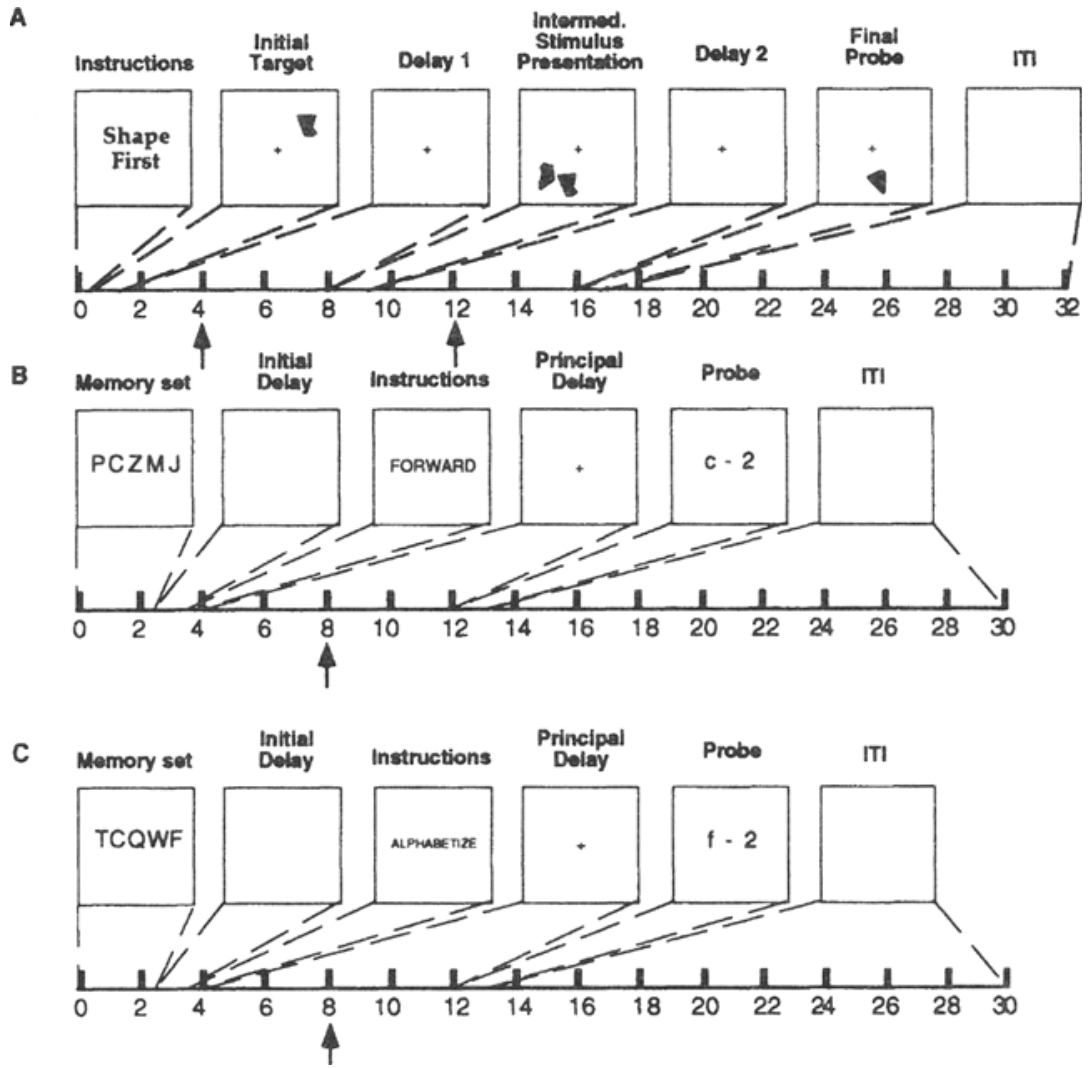

Figure 1. Schematic illustration of trials from each of our three event-related fMRI experiments. Each box represents a stimulus display event, and the dotted lines connecting each box with a timeline represent the sequence and duration of each of these events. Numbers along the timelines represent time in seconds; arrows along the timelines represent the placement of covariates positioned to detect variance in the fMRI signal attributable to delay-period activity. (A) Spatialobject delayed recognition: $A$ "what"-then“where" trial (Postle \& D'Esposito, 1999). (B) Letter-delayed item recognition: A Forward 5 trial from D'Esposito, Postle, Ballard, and Lease (1999) or from Postle, Berger, and D'Esposito (1999). (C) Letter delayed item recognition: An Alphabetize 5 trial from D'Esposito, Postle, Ballard, and Lease (1999) or from Postle, Berger. and D'Esposito (1999).

itatively distinct component of the behavioral trials (typically, for delayed-recognition tasks, target, delay, probe) with a series of covariates that were entered into a general linear model (GLM) modified for autocorrelated observations (Worsley \& Friston, 1995). Each covariate was composed of an HRF positioned appropriately to represent neural activity associated with one of the task components (Zarahn et al., 1997b). The least squares solution of the modified GLM of the dependent data (i.e., of the fMRI time series) yielded parameter estimates (i.e., $\beta$ values) that were associated with each covariate of interest. These parameter estimates were interpreted as indices of the extent to which their corresponding covariates of interest explained the dependent data. Statistical maps were generated by computing $t$ statistics associated with linear combinations of the covariates of interest. More details on our method can be found in Postle, Zarahn, and D'Esposito (2000).

\section{Regions of Interest}

Our analyses were performed within four frontal lobe ROIs: anterior and inferior regions of inferior frontal gyrus corresponding to Brodmann's area 47; superior and posterior regions of inferior frontal gyrus corresponding to Brodmann's areas $44 / 45$; middle frontal gyrus corresponding to Brodmann's areas $9 / 46$; and the cor- tex bounding the superior frontal sulcus (SFS) within Brodmann's areas $8 / 6$. Our general method for defining ROIs is detailed in Postle and D'Esposito (1999). The border between areas 47 and 44/45 was defined as the portion of inferior frontal gyrus $5 \mathrm{~mm}$ inferior to the ventral-most extent of area 46 .

\section{Hypothesis Testing}

We adopted three different analysis strategies for the retrospective analyses of our event-related fMRI data sets: single-participant analyses, relative effect size group analyses, and normalized voxel count group analyses.

Single-participant analyses. These analyses permitted us to maintain the high spatial resolution afforded by $\mathrm{fMRI}$ and to detect intersubject variability. Single-participant analyses represent the most direct way to assess the relative sensitivity of fMRI activity in a voxel or a region to two different levels of an experimental factor. (For example, as we shall see, whether dorsolateral PFC demonstrates greater delay-period activity for spatial or for object stimuli.) Our single-participant analyses treated each participant as a case study, permitting us to assess replication of (as well as variation in) effects across individual cases. In essence, data from 6 participants performing the same task would represent a single result with five 
replications, not dissimilar to how data from different monkeys are treated in electrophysiological studies. It is important to note that the contrasts representing single-participant analyses in each of the original analyses performed with the data presented in this report (D'Esposito, Postle, Ballard, \& Lease, 1999; Postle et al., 1999; Postle \& D'Esposito, 1999) featured in excess of 1,100 effective degrees of freedom. Thus this approach was sufficiently powerful for our present purposes.

Group analyses. We employed two different types of group analyses: relative effect size analyses and normalized voxel count analyses. We employed relative effect size analyses when comparing effects of two conditions within the same voxels, either to assess the generality of effects observed in single-participant analyses or to test for the presence of effects that may have been too subtle to achieve statistical significance in our single-participant analyses but that may have been reliable at the group level. These analyses were performed in three steps. First, a spatially averaged time series was extracted from the data of each participant, either by identifying a subset of functionally homogenous voxels within a particular region (e.g., all dorsolateral PFC voxels demonstrating the "main effect" of delayperiod activity when collapsed across trial type, as identified with the contrast [delay spatial + delay $_{\text {object }}$ ]), or by integrating across every voxel within an ROI. (The former approach is generally preferred because it limits the analysis to voxels whose function is believed to be related to the task in question; the ROI-wide approach must be taken, however, either in instances in which the effect in question is too subtle to be identified with a main effect contrast, or in instances in which the representations of the functions represented by the two conditions are so strongly segregated that "main effect" voxels cannot be identified.) Second, the spatially averaged time series (one from each participant) were interrogated with the contrast of theoretical interest (e.g., the two-tailed contrast [delay spatial - delay $_{\text {object }}$ ), the resultant $t$ values from which would index the relative effect size of this contrast for each participant. Third, these $t$ values, one from each participant, were entered into a paired $t$ test to assess the reliability of the effect at the group level. (To continue the example used in this section, the $t$ test would determine whether the mean $t$ value was different from 0 . If it were, a significantly negative effect would be interpreted as significantly greater object than spatial delay-related activity at the group level, a significantly positive effect as the converse.) More detail about single-participant and relative effect size group analyses, including the use of $t$ values as dependent measures, is presented in Postle, Zarahn, and D'Esposito (2000).

Normalized voxel count analyses were employed in the assessment of the relative importance of different regions in supporting the same function (e.g., the degree of lateralization of verbal working memory function in ventrolateral PFC). These analyses were performed in four steps. First, we generated for each participant's data statistical parametric maps (thresholded to an ROI-wise $\alpha=.05$ (Zarahn, Aguirre, \& D'Esposito, 1997a) to identify all the voxels displaying the function in question (e.g., delay-period activity for letters). Second, we normalized the number of suprathreshold voxels identified in Step 1 by dividing the number of suprathreshold voxels by the number of voxels in the ROI. Third, we generated for each participant a single-value index by subtracting the two normalized voxel counts (e.g., the sum of [(left 44/45 normalized voxel count) - (right 44/45 voxel count)] would yield a lateralization index). Finally, we assessed the reliability at the group level of this index by entering the indices from each participant's data into either an analysis of variance (ANOVA) or a paired $t$ test, the former when we were testing hypotheses concerning more than two ROIs, and where each participant was thus contributing more than two scores to the analysis. Of critical importance to this (and any) voxel-counting method is the ability to define objectively a threshold for determining the significance of task-related activity of individual voxels. The approach used for the three data sets reanalyzed for this report, application of Bonferroni correction for the number of voxels in an ROI to each voxel within a spatially unsmoothed statistical map, yields an ROI-wise false positive rate of $p=.05$ (Postle et al., 2000; Zarahn et al., 1997a).

Both types of group analyses were performed as random effects models, which permit generalization of results obtained from a sample to the population represented by that sample. This inferential step cannot be made with the fixed effects group analyses that have been employed in the majority first-generation neuroimaging studies (Friston et al., 1999; Woods, 1996).

\section{RESULTS}

This section is organized according to the particular model (as listed in Table 1) that each analysis was intended to address.

\section{Functional Organization by Stimulus Material}

Model A: Dorsolateral and ventrolateral regions of frontal cortex may differentially support working memory for spatial and object stimuli, respectively (Courtney, Ungerleider, Keil, \& Haxby, 1996; Smith \& Jonides, 1999; Smith et al., 1995). The results of our event-related fMRI experiment failed to generate evidence, in singleparticipant analyses and in a relative effect size group analysis, for anatomical segregation of spatial and object working memory function in frontal cortex (Postle \& D'Esposito, 1999) (Figure 2). Indeed, our results were remarkable for the extent to which they demonstrated much greater variability of localization of PFC delayperiod activity within conditions but across participants than they did within participants and across condition. These results were thus incompatible with models positing areal segregation of working memory function by stimulus material.

It remained possible, however, that activity attributable to stimulus encoding processes (as indexed in our study by target-related activity) and/or response selection and execution processes (as indexed in our study by proberelated activity) may adhere to a dorsal/ventral segregation in PFC according to the type of stimulus domain being remembered. Indeed, segregation of encoding- and/ or response-related activity could yield evidence for dorsal/ventral segregation in block design data, despite the absence of such segregation in delay-specific activity. The single-participant analyses that we performed for the present report, however, did not show any reliable evidence for a systematic segregation of object- and spatial-related activity attributable to either the target or the probe components of the task (Figure 3 ). In the target analyses, no participants demonstrated significant differences in activity in area 47 or areas $44 / 45$, and only 1 participant demonstrated greater object than spatial activity in areas $9 / 46$. In the probe analyses, 1 participant demonstrated greater object than spatial activity in area 47, 1 participant demonstrated greater object than spatial activity and a 2 nd participant the converse in areas $44 / 45$, and 1 participant demonstrated both object- and spatial- 

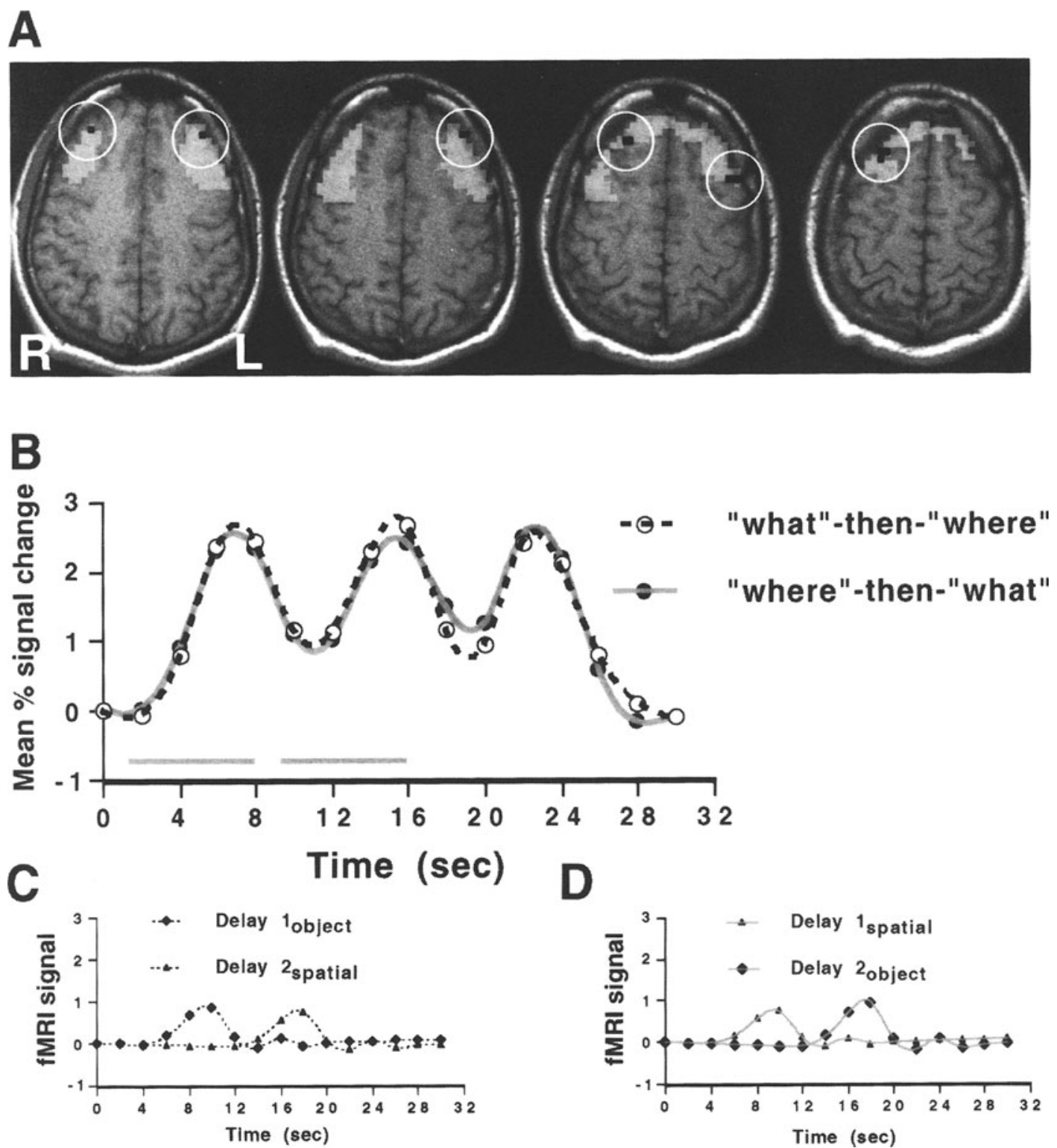

Figure 2. (A) Spatial/object delayed recognition: Voxels identified as having significant spatial delay-period activity in dorsolateral PFC of Participant 3 (Postle \& D'Esposito, 1999). Activated voxels are depicted in black and circled. Translucent white overlay represents the areas $9 / 46 \mathrm{ROI}$. (B) Trial-averaged time series data from the voxels depicted in panel $A$. Note that object delay-period activity is comparable to spatial delay-period activity in both trial types, even though the property of object delay-period sensitivity is independent of the way in which these voxels were selected. Gray bars along the horizontal axis represent the duration of delay periods in this task. (C) Delay 1 and Delay 2 covariates corresponding to the "what"-then-"where" data in panel B, scaled by their parameter estimates, illustrating quantitatively that the delay effect in these voxels was comparable during Delays 1 and 2. (D) Delay 1 and Delay 2 covariates corresponding to the "where"-then-"what" data in panel B, scaled by their parameter estimates, illustrating quantitatively that the delay effect in these voxels was also comparable during Delays 1 and 2.

specific voxels in areas $9 / 46$, whereas a 2 nd participant demonstrated greater object than spatial activity in the left hemisphere of this ROI. Similarly, relative effect size group analyses failed to yield evidence for reliable differences in PFC activity by stimulus material during either target or probe components of the trial, as illustrated by the mean data in Table $2[F(1,4)$ values $<1.6]$.
Model B: Left and right mid-dorsolateral PFC may differentially support working memory for spatial and object stimuli, respectively (Baker, Frith, Frackowiak, \& Dolan, 1996; Belger et al., 1998; McCarthy et al., 1996); and Model C: Left and right ventrolateral PFC may differentially support working memory for spatial and $o b$ ject stimuli, respectively (D'Esposito, Aguirre, Zarahn, \& 
TARGET

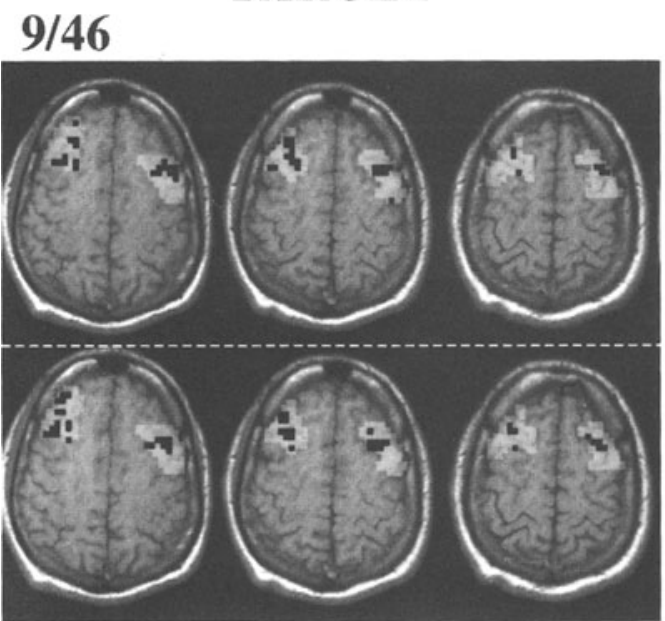

$44 / 45$

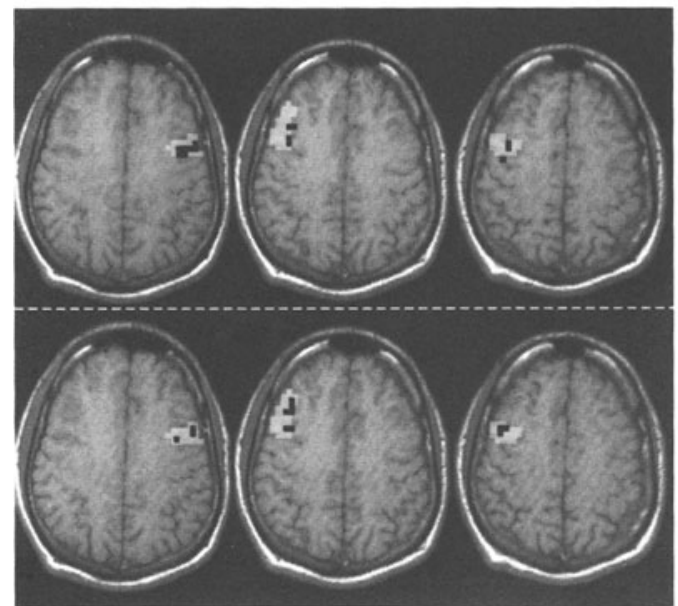

47

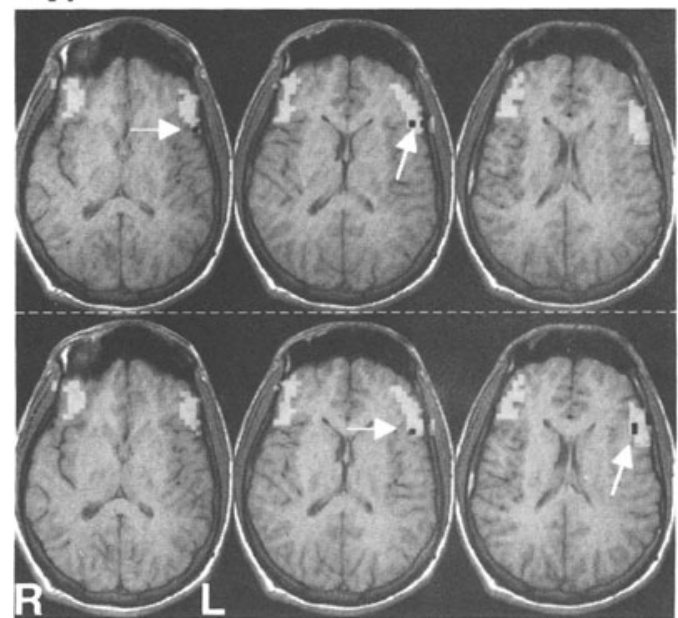

PROBE

\section{9/46}

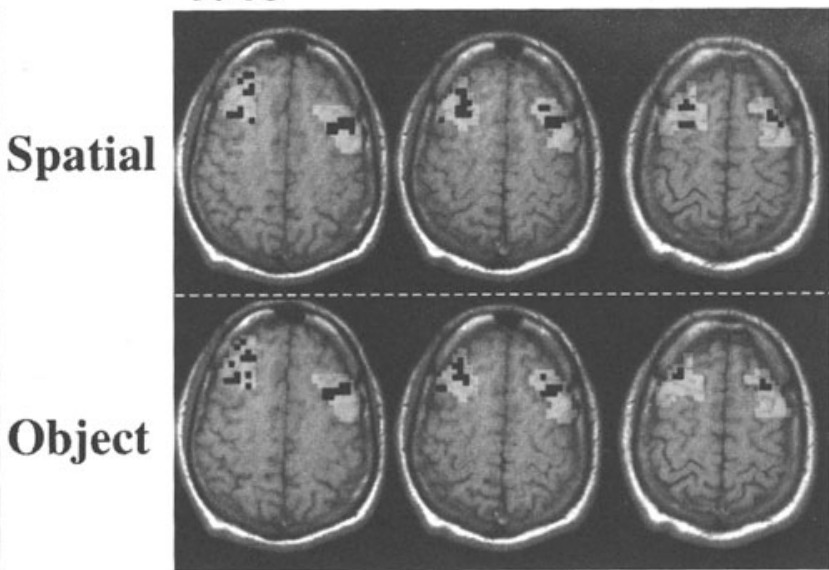

\section{$44 / 45$}
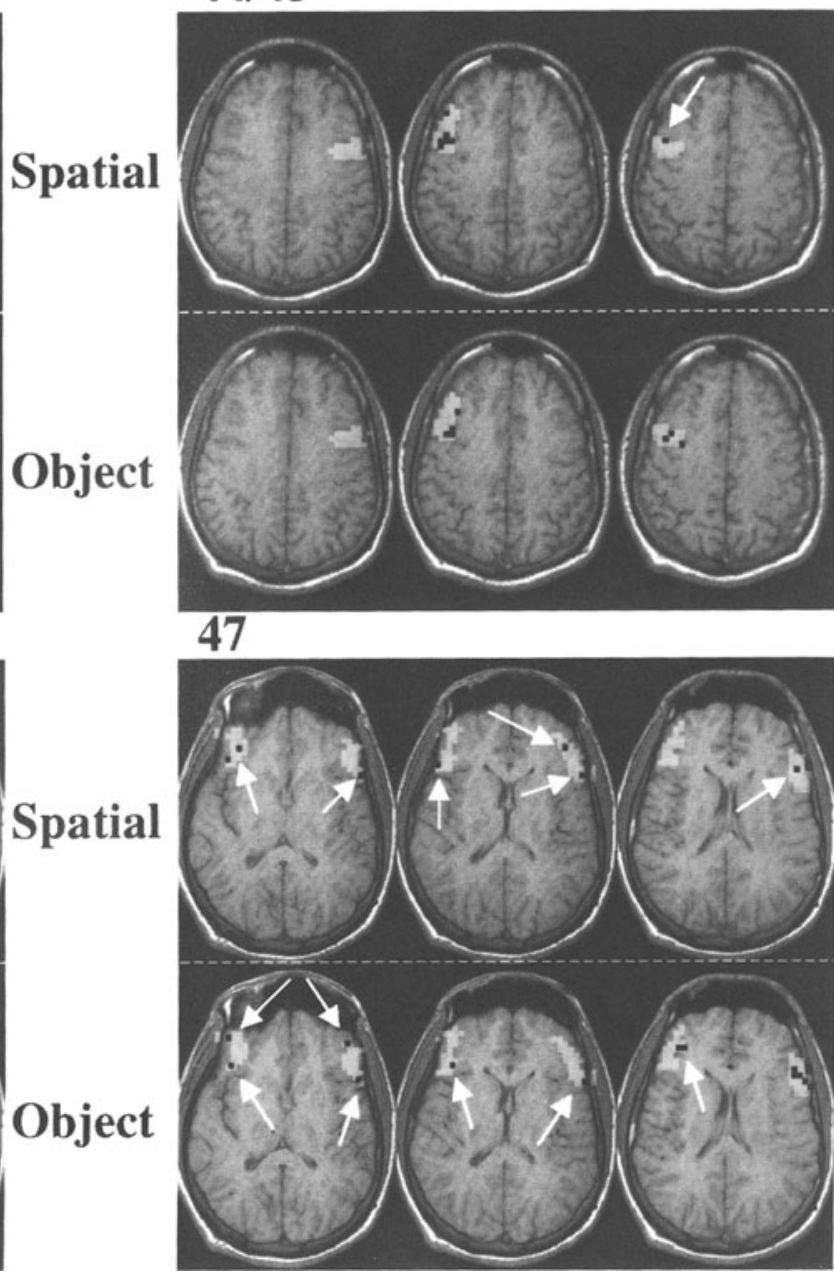

Figure 3. Spatial/object delayed recognition: Target- and probe-related activity, by ROI and stimulus type, in Participant 3 (Postle \& D'Esposito, 1999), illustrating a high degree of overlap between spatial- and object-related activity in each ROI. Significantly activated voxels are depicted in black, and translucent overlays represent the ROI corresponding to each panel. Arrows highlight some individual voxels for ease of identification. 
Table 2

Group Mean Stimulus Domain Effects

\begin{tabular}{lccccc} 
& \multicolumn{2}{c}{ Target } & & \multicolumn{2}{c}{ Probe } \\
\cline { 2 - 3 } \cline { 5 - 6 } ROI & $M$ & $S E$ & & $M$ & $S E$ \\
\hline 47 & .27 & .17 & -.04 & .44 \\
$44 / 45$ & -.28 & .58 & .59 & .86 \\
$9 / 46$ & -.29 & .4 & .43 & .58 \\
\hline
\end{tabular}

Note-Indexed by the results of the two-tailed contrast (Covariate - Covariate spatial ), where "Covariate" corresponds to target or probe trial component ( $t$ values). Positive values indicate greater object than spatial effects, negative values the converse. ROI, region of interest.

Ballard, 1998; Smith et al., 1995). The results of our single-participant analyses, as published in Postle and D'Esposito (1999), were incompatible with models proposing lateralized segregation of spatial versus object working memory activity in PFC. For the present report we assessed whether lateralization effects may be too subtle to detect at the individual participant level, but nonetheless reliable at the group level, with a relative effect size analysis. We first performed this analysis on maineffect-of-delay voxels, but discovered that several participants did not have main-effect-of-delay voxels in both hemispheres of certain ROIs. We therefore also performed these analyses on all voxels within each ROI. The results of these analyses, presented in Table 3, revealed no reliable lateralization effects in areas $44 / 45,9 / 46$, or the SFS ROI, and only a suggestion of a lateralization trend in area $47[t(5)=2.21, p=.09]$, with object delay-period activity lateralized to the left hemisphere, and spatial to the right.

Model D: Working memory for verbal material may be preferentially processed in the left hemisphere of PFC (Awh et al., 1996; Gabrieli, Poldrack, \& Desmond, 1998; Smith \& Jonides, 1999; Smith, Jonides, Marshuetz, \& Koeppe, 1998). We performed normalized voxel count group analyses on the data from all 12 participants in the letter delayed item recognition tasks. Tabulation of our results indicated that a comparable number of participants demonstrated bilateral delay-period activity in the areas $9 / 46 \mathrm{ROI}$ (left $=10 / 12$ participants; right $=7 / 12$ participants) and in the area 47 ROI (left $=6 / 12$ participants; right $=6 / 12$ participants). In area 44/45 ROI, although markedly more participants demonstrated delay- period activity in the left $(9 / 12)$ than in the right $(5 / 12)$ hemisphere, this difference failed to reach significance by a chi-square test. The group lateralization data, presented in Table 4 , indicated that there were no reliable lateralization effects in areas $9 / 46$ or area 47 , but a significant effect of more left than right hemisphere activity in area $44 / 45[t(11)=2.3, p<.05$; Table 4]. Figure 4 illustrates activity from delay-sensitive voxels of the left hemisphere of Brodmann's areas 44/45 in a representative participant from Postle et al. (1999).

\section{Functional Organization by Process}

Model E: Dorsolateral PFC may be recruited preferentially to support manipulation of items held in working memory (D'Esposito et al., 1998; Owen, Evans, \& Petrides, 1996; Owen et al., 1999). In two previous studies employing the letter delayed item recognition task, featuring a total of 12 participants, dorsolateral PFC activity in every participant was significantly greater in trials during which information held in working memory was manipulated. The same was true in ventrolateral PFC for only 4 of these 12 participants (D'Esposito, Postle, Ballard, \& Lease, 1999; Postle et al., 1999). The uniformity of these results across participants, arising from two studies designed explicitly to test Model E, obviated the need for us to perform a group analysis for this report. The results of D'Esposito, Postle, Ballard, and Lease (1999) and of Postle et al. (1999) were consistent with the hierarchical processing model proposed in Model E in that they revealed a consistently greater contribution of dorsal than ventral PFC to manipulation processes.

Model F: Dorso- and ventrolateral PFC may, to the relative exclusion of other mnemonic processes, support manipulation and maintenance, respectively, of items held in working memory (Owen et al., 1999; Smith \& Jonides, 1999; Smith et al., 1998). We have previously reported that, in two event-related fMRI studies employing the letter delayed item recognition task, activity during the delay period was found in both dorsolateral and ventrolateral PFC during both Forward and Alphabetize trial types (D'Esposito, Postle, Ballard, \& Lease, 1999; Postle et al., 1999) (Figure 5). As noted in the section on Model E, data from each participant in both studies also revealed a reliably greater effect of alphabetization-

Table 3

Group Analyses of Lateralization of Object Versus Spatial Delay-Period Activity, From Postle and D'Esposito (1999), by Main-Effect-of-Delay Voxels and by ROI

\begin{tabular}{|c|c|c|c|c|c|c|c|c|c|}
\hline \multirow{2}{*}{$\begin{array}{l}\text { Region of } \\
\text { Interest }\end{array}$} & \multicolumn{5}{|c|}{$\begin{array}{l}\text { Main-Effect-of-Delay Voxels } \\
\text { Lateralization Index }\end{array}$} & \multicolumn{4}{|c|}{$\begin{array}{c}\text { Entire ROI } \\
\text { Lateralization Index }\end{array}$} \\
\hline & $M$ & $S E$ & $n$ & $t$ Value & $d f$ & $M$ & $S E$ & $t$ Value & $d f$ \\
\hline 47 & 1.6 & 1.5 & 3 & - & & .7 & .32 & $2.21^{*}$ & 5 \\
\hline $44 / 45$ & -1.81 & & 1 & - & & -.94 & .78 & -1.2 & 5 \\
\hline $9 / 46$ & -.77 & .82 & 6 & -.93 & 5 & .06 & .83 & .07 & 5 \\
\hline SFS & 2.4 & .99 & 4 & 2.27 & 3 & .41 & .59 & .69 & 5 \\
\hline
\end{tabular}

Note-Positive values indicate that object effects are relatively greater in the left than in the right hemisphere, negative values the converse. SFS, superior frontal sulcus. $\quad{ }^{*} p=$ .09 . 
Table 4

Group Analyses of Lateralization of Delay-Period Activity in Letter Delayed Item Recognition, From

D'Esposito, Postle, Ballard, and Lease (1999)

and Postle, Berger, and D'Esposito (1999)

\begin{tabular}{|c|c|c|c|c|}
\hline \multicolumn{5}{|c|}{ Lateralization Index } \\
\hline Region of Interest & $M$ & $S E$ & $t$ Value & $d f$ \\
\hline 47 & -.011 & .01 & -1.2 & 11 \\
\hline $44 / 45$ & .013 & .006 & $2.3^{*}$ & 11 \\
\hline $9 / 46$ & .001 & .004 & .3 & 11 \\
\hline
\end{tabular}

Note-Positive values indicate greater left- than right-hemisphere activity, negative values indicate the converse. ${ }^{*} p<.05$.

related than of maintenance-related activity in dorsolateral PFC (D'Esposito, Postle, Ballard, \& Lease, 1999; Postle et al., 1999). Model $F$ would predict that maintenancerelated activity within these same 12 participants would be greater in ventrolateral PFC than in dorsolateral PFC. Although this prediction was not supported by our single-participant analyses (D'Esposito, Postle, Ballard, \& Lease, 1999; Postle et al., 1999), for the present report we also tested this model by performing a normalized voxel count analysis on data from these 12 participants. In this analysis we assessed the proportion of voxels sensitive to maintenance across the delay of five items in "forward" order in each of the three PFC ROIs. The ANOVA, which compared extent of maintenance-related activity across the three ROIs, revealed no effect of ROI $[F(2,22)=1.22$; Table 5]. That is, there were not significantly more voxels demonstrating maintenance-related activity in either area 47 or areas $44 / 45$ than in areas $9 / 46$. The result of this group analysis, consistent with our previous single-participant analyses (D'Esposito, Postle, Ballard, \& Lease, 1999; Postle et al., 1999), is therefore inconsistent with Model $\mathrm{F}$, which predicted greater maintenance-related activity in ventrolateral PFC than in dorsolateral PFC.

\section{DISCUSSION}

\section{Evaluating Models of PFC Functional Organization by Stimulus Material}

Our assessment of models positing topographical organization of PFC working memory functions by stimulus material yielded mixed results. We found no evidence for dorsal/ventral segregation of spatial versus object stimulus material processing during the target, delay, or probe components of the trial (Table 2). These results are thus inconsistent with Model A, as articulated by Smith and Jonides (1999), Smith et al. (1995), and Courtney et al. (1996). There are many reasons why the model of a dorsal/ventral segregation of spatial and nonspatial working memory function in the human has been enormously influential in framing the cognitive neuroscientific approach to working memory research. First, it has the appeal of parsimony because it represents a direct extension into the frontal cortex of the dorsal/ventral orga- nization of the posterior visual system (Ungerleider \& Haxby, 1994; Ungerleider \& Mishkin, 1982). Second, it is consistent with previous neurobiological research (e.g., Funahashi, Bruce, \& Goldman-Rakic, 1990, 1993; Goldman \& Rosvold, 1970; Goldman-Rakic, 1987; Gross, 1963; Mishkin \& Manning, 1978; Passingham, 1975; Wilson et al., 1993; but see Rainer, Asaad, \& Miller, 1998; Rao et al., 1997; Rushworth, Nixon, Eacott, \& Passingham, 1997). Finally, there is persuasive psychophysical evidence for a dissociation of working memory for "what" and "where" (Della Sala, Gray, Baddeley, Allamano, \& Wilson, 1999; Owen, Iddon, Hodges, Summers, \& Robbins (1997) Postle, Jonides, Smith, Corkin, \& Growdon, 1997; Smith, Jonides, Koeppe, Awh, Schumacher, \& Minoshima, 1995; Tresch, Sinnamon, \& Seamon, 1993).

When the record of cognitive neuroscientific empirical results is brought to bear on this question, however, the evidence is resoundingly inconsistent with this model. Neuroimaging studies (many of them first-generation neuroimaging studies) that have failed to yield evidence for a dorsal/ventral organization of spatial versus object working memory function in human frontal cortex include Smith et al. (1995); McCarthy et al. (1996); Baker et al. (1996); Owen et al. (1998); Oster, Snow, Miller, and Corkin (1997); D'Esposito et al. (1998); Belger et al. (1998); Postle and D'Esposito (1999); Postle, Stern, Rosen, and Corkin (2000); and Nystrom et al. (2000). Only one laboratory, in contrast, has consistently reported evidence for a double dissociation between activity in dorsal and ventral regions of human lateral frontal cortex during the maintenance of spatial versus nonspatial information using functional neuroimaging, as represented in the publications of Courtney, Petit, Maisog, Ungerleider, and Haxby (1998); Courney et al. (1996); Ungerleider, Courtney, and Haxby (1998); and Haxby, Petit, Ungerleider, and Courtney (2000). The methods represented in these studies, too, span first- and second-generation neuroimaging techniques. One salient difference between the methods of Courtney and collaborators and those of most of the studies cited earlier in this paragraph is the use of faces as nonspatial stimuli in the Courtney studies. It could be, for reasons that have not yet been understood, that working memory for face stimuli does not recruit dorsal regions of frontal cortex to the same extent as working memory for many other types of nonspatial stimuli. Apart from this difference, satisfying explanations for the discrepancy between studies that do and do not find evidence for dorsal/ventral segregation of spatial and nonspatial working memory function in frontal cortex remain elusive.

Our test of lateralization of working memory functions by visuospatial stimulus material yielded no evidence for lateralization of delay-period activity in middle frontal gyrus (Table 3), a result inconsistent with Model B (Baker et al., 1996; Belger et al., 1998; McCarthy et al., 1996). Our analyses did provide, however, evidence for a subtle trend toward lateralization of delay-period ac- 

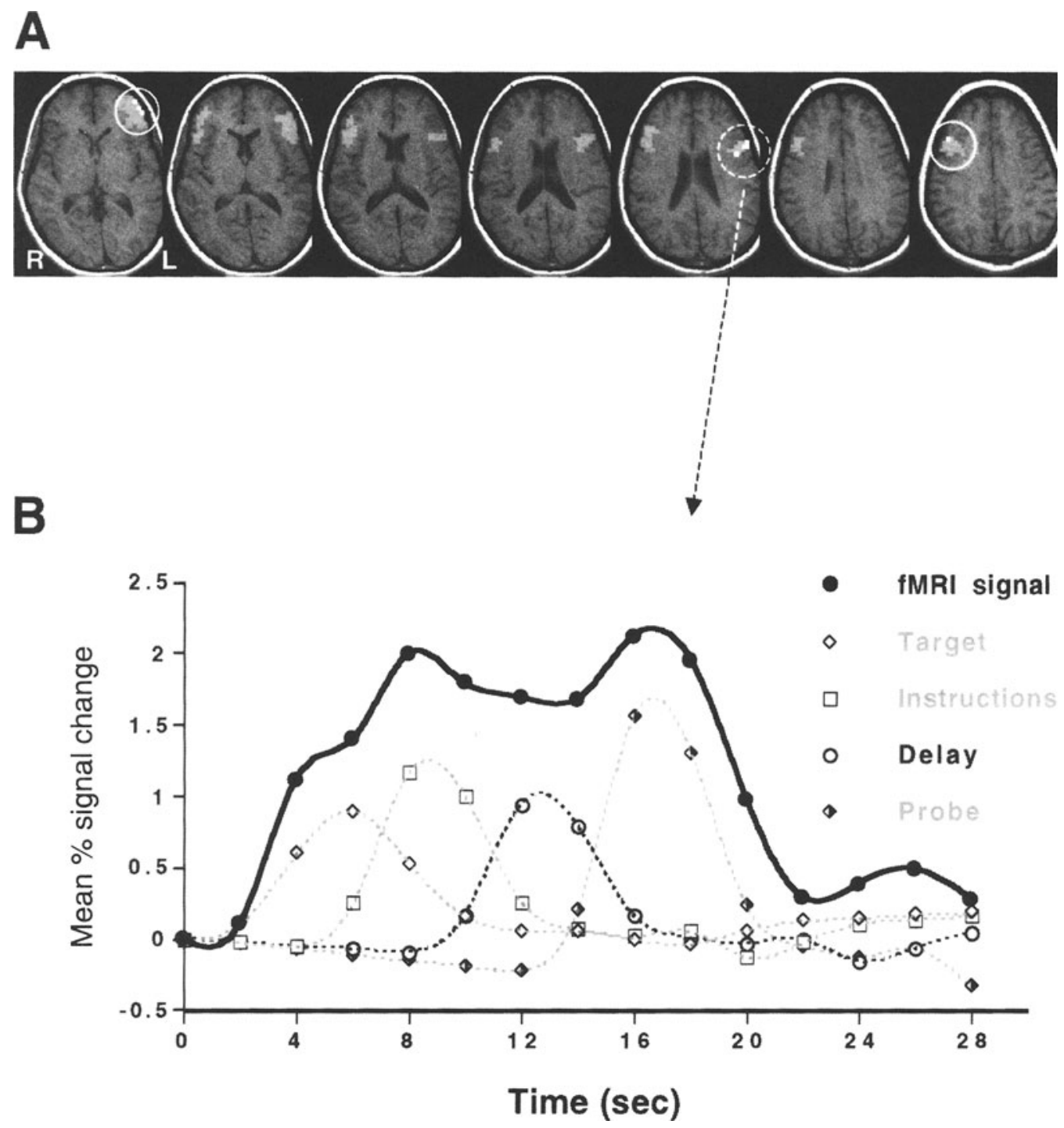

Figure 4. (A) Letter-delayed item recognition: Significant delay-period activity (white voxels) during Forward 5 trials in areas 44/45 in Participant 1 (Postie, Berger, \& D'Esposito, 1999). Dotted circle identifies voxels in the left hemisphere of Brodmann's area 44 whose time series is depicted in panel B; solid circles highlight additional delay-sensitive voxels whose activity is not depicted in panel B. (B) Trial-averaged time series, averaged across the four voxels identified in panel $A$, and associated covariates, scaled by their parameter estimates, modeling each of the four distinct components of the trial. The behavior of the covariates illustrates quantitatively that these voxels were significantly active during all components of the trial, not just the delay period.

tivity in ventrolateral area 47 , with object delay-period activity lateralized to the left hemisphere and spatial delay-period activity lateralized to the right hemisphere (Table 3). Although our design, with $5 d f$ for random effects group analyses, featured sufficient statistical power to detect stimulus-material-related effects in posterior cortical areas (Postle \& D'Esposito, 1999), it could be that the trend toward lateralization in ventrolateral PFC is simply too subtle to be detected with the number of participants in our data set. This tentatively positive result of our relative effect size analysis in area 47 , al- though it must be interpreted with caution at the present time, is provisionally consistent with Model C (D'Esposito et al., 1998; Smith et al., 1995).

In our assessment of evidence for lateralization of delay-specific working memory activity for verbal stimuli, a prediction of Model D (Awh et al., 1996; Gabrieli et al., 1998; Smith \& Jonides, 1999; Smith et al., 1998), we found no evidence for differences in dorsolateral PFC or in anterior ventrolateral PFC area 47, but we did find evidence for greater recruitment of left than right hemisphere in posterior ventrolateral PFC areas 44/45 (Ta- 
Table 5

Group Data of Mean Number of Voxels (per ROI) Sensitive to Delay-Period Activity in Letter-Delayed Item Recognition, From D'Esposito, Postle, Ballard, and Lease (1999) and Postle, Berger, and D'Esposito (1999)

\begin{tabular}{cccc}
\hline & \multicolumn{3}{c}{ Normalized No. Voxels } \\
\cline { 2 - 4 } Region of Interest & $M$ & $S E$ & $n$ \\
\hline 47 & .0053 & .0018 & 12 \\
$44 / 45$ & .0143 & .0043 & 12 \\
$9 / 46$ & .0103 & .0026 & 12 \\
\hline
\end{tabular}

ble 4). This result is thus consistent with the results of earlier PET studies (Awh et al., 1996; Paulesu, Frith, \& Frackowiak, 1993) and with models positing an important role for Broca's area in the working memory rehearsal and maintenance of verbal stimulus material (Gabrieli et al., 1998; Henson, Burgess, \& Frith, 2000; Smith \& Jonides, 1999; Smith et al., 1998).

\section{Evaluating Models of PFC Organization by Process}

The results of our assessment of models of PFC organization by process permit us to clarify and extend our current understanding of these models. Published results from two event-related fMRI studies of the effects of maintenance versus manipulation of items held in working memory (D'Esposito, Postle, Ballard, \& Lease, 1999; Postle et al., 1999) confirm the central hypothesis of Model E, as formulated from first-generation neuroimaging studies (D'Esposito et al., 1998; Owen et al., 1996; Owen et al., 1999), that dorsolateral PFC is recruited preferentially to support manipulation of items held in working memory. Some theorists have suggested, in an extension of Model $\mathrm{E}$ that we have presented in this report as Model $\mathrm{F}$, that this organization by processing manifests itself as a double dissociation in which dorsolateral PFC preferentially supports manipulation processes, and ventrolateral PFC supports maintenance pro-
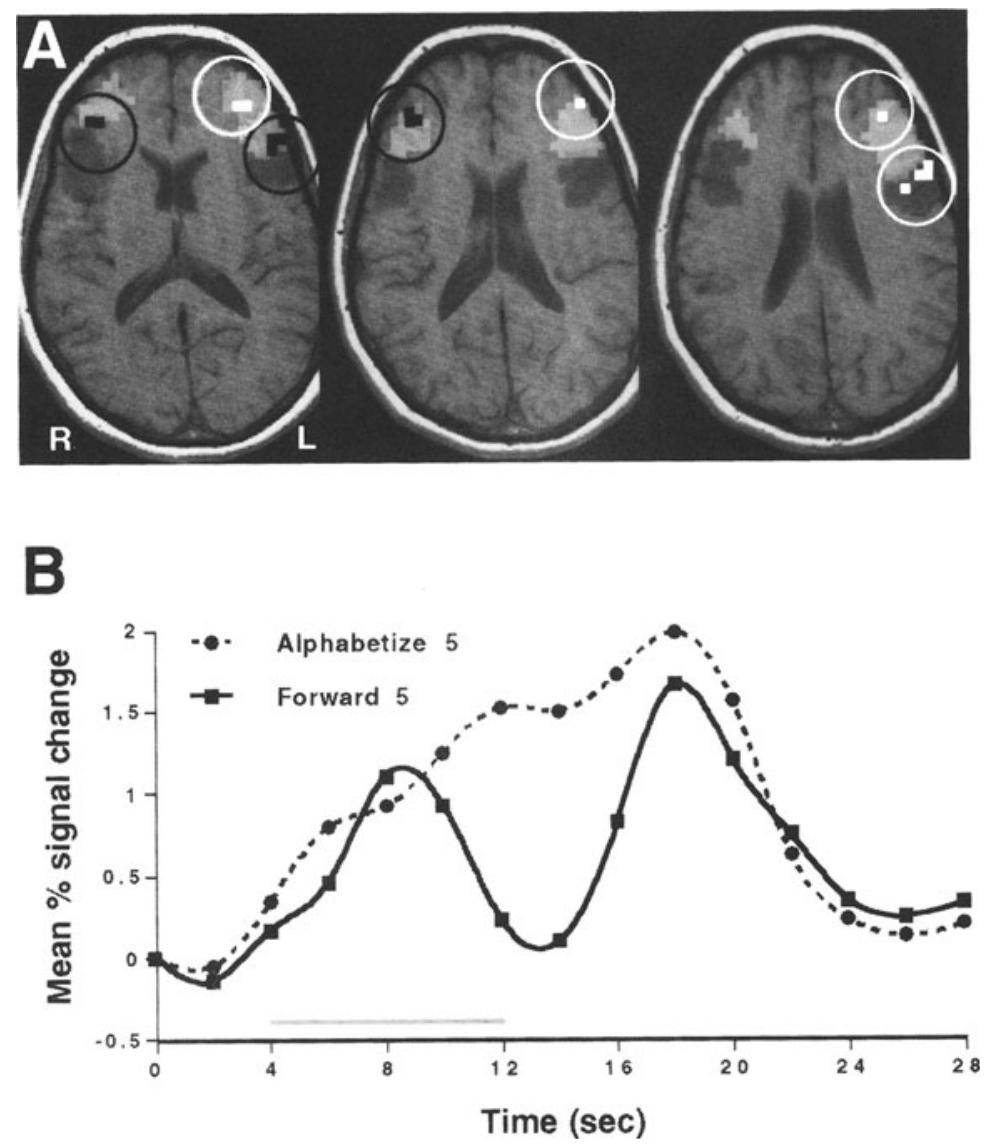

Figure 5. (A) Letter-delayed item recognition: Significant delay-period activity during Alphabetize 5 (black voxels) and Forward 5 (white voxels) in Participant 1 (Postle, Berger, \& D'Esposito, 1999). Note that alphabetization-sensitive voxels were found only in areas $9 / 46$ (translucent white overlay), whereas maintenance-sensitive voxels were found in areas 9/46 and areas 44/45 (translucent black overlay). (B) Trial-averaged time series data from the alphabetizationsensitive voxels identified in panel $A$. Note that these voxels did not demonstrate delay-specific activity during Forward 5 trials. 

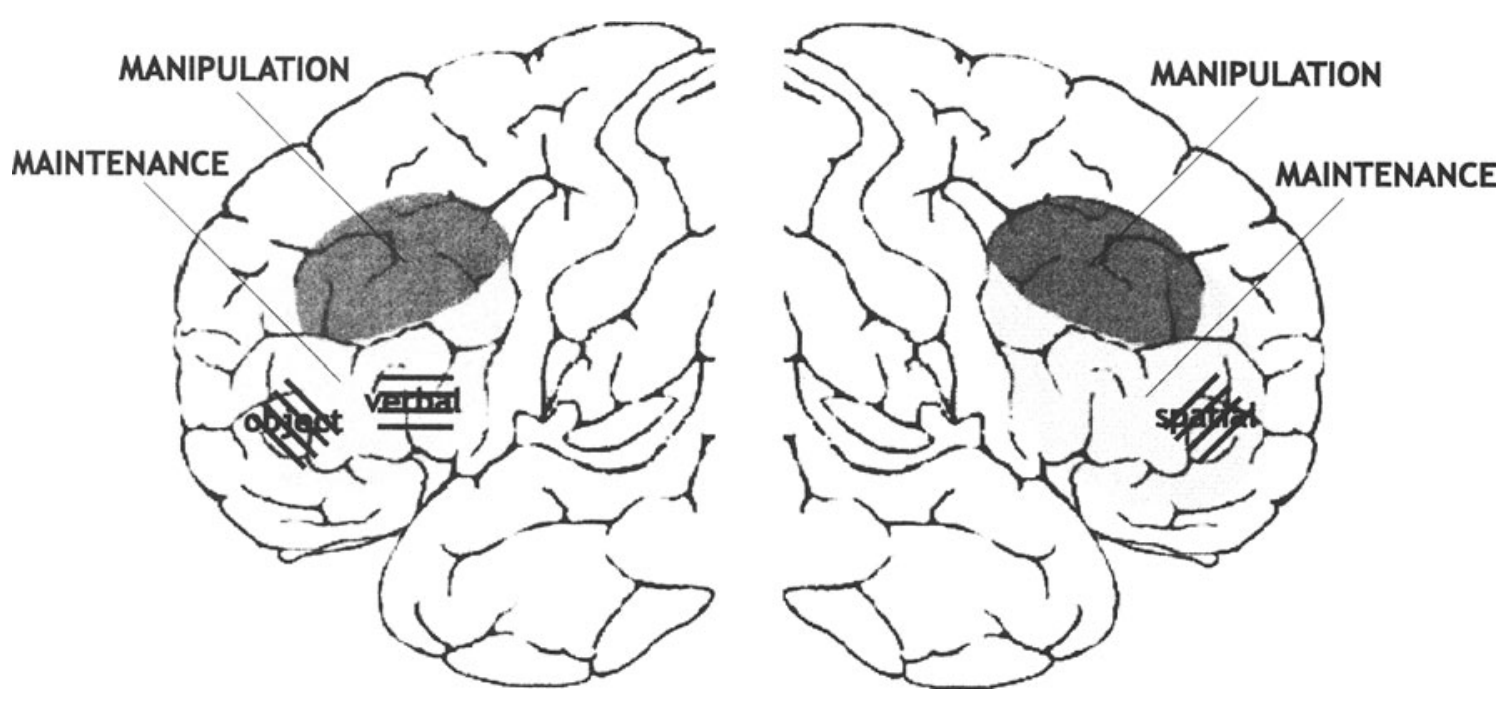

Figure 6. A schematic illustration of our hybrid model of the organization of working memory function in PFC. The left hemisphere is on the left.

cesses (Owen et al., 1999; Smith \& Jonides, 1999; Smith et al., 1998). This strong version of the maintenance/ manipulation model of PFC organization was not supported, however, by our additional analyses. Rather, we found comparable representation of working memory maintenance activity in dorso- and ventrolateral PFC (Table 5).

\section{Toward a Unified Model of the \\ Working Memory Functions of PFC}

The process of reassessing models of PFC working memory function has permitted us to reject some of the models derived from first-generation neuroimaging data, and to refine others. The outcomes of this empirical exercise present us with an opportunity to synthesize what we have learned into a revised model of the working memory functions of PFC. Our hybrid model is reminiscent of other recently published models (e.g., Smith \& Jonides, 1999) in that it recognizes that organization-bystimulus-domain and organization-by-process models are fundamentally orthogonal to one another, and that the organization of working memory function in PFC likely reflects principles drawn from both. Our model nevertheless differs in important details from any other model published to date by virtue of the insights that we have gained from the analyses presented in this report. The details of this model, depicted in Figure 6, are as follows: (1) Processes supporting working memory maintenance of verbal information are left lateralized in ventrolateral PFC areas 44 and 45. (2) Processes supporting working memory maintenance are nonetheless broadly distributed, because dorsolateral PFC is activated by these processes to an extent comparable to ventrolateral PFC.
(3) Processes supporting working memory maintenance of spatial and nonspatial visual stimuli are also broadly distributed, and they only dissociate to a subtle degree in anterior ventrolateral area 47 , where object maintenance may be preferentially left lateralized, and spatial maintenance may be preferentially right lateralized. (4) The processes supporting manipulation of information held in working memory are largely confined to dorsolateral PFC, bilaterally.

An important feature of our model is that many regions of PFC can support more that one working-memoryrelated process (D'Esposito, Postle, Berger, \& Taich, 1999; D'Esposito, Postle, \& Rypma, in press), a principle that is also seen in the monkey (Chafee \& GoldmanRakic, 1998; Fuster, 1997). Dorsolateral PFC, for example, supports manipulation processes, verbal maintenance processes, visuospatial maintenance processes, and visuofeatural maintenance processes. Areal segregation of processes tends to manifest itself in a graded fashion, rather than as abrupt circumscription of boundaries.

Although many questions about the functional organization of working memory processes in the human brain remain to be answered, we are optimistic that many newer techniques available to the cognitive neuroscientist, including event-related fMRI, magnetoencephalography, and repetitive transcranial magnetic stimulation, will contribute to a further refinement of our models. Salient goals for future research include elucidating the cognitive and neural architecture of nonmnemonic executive control processes that fall under the rubric of the central executive (Baddeley, 1986), better characterizing the interactions of posterior and prefrontal systems in the support of working memory performance (Petrides, 1994; 
Postle et al., 1999), and determining the extent to which the organizational principles put forward here correspond to those governing the functional organization of longterm memory in PFC (Wagner, 1999).

\section{REFERENCES}

Aguirre, G. K., ZarahN, E., \& D'Esposito, M. (1998). The variability of human, BOLD hemodynamic responses. Neurolmage, 8,360 369

Awh, E., Jonides, J., Smith, E. E., Schumacher, E. H., Koeppe, R. A., \& KATZ, S. (1996). Dissociation of storage and rehearsal in verbal working memory: Evidence from positron emission tomography. Psychological Science, 7, 25-31.

BADDELEY, A. D. (1986). Working memory. Oxford: Oxford University Press.

Baker, S. C., Frith, C. D., Frackowiak, R. S. J., \& Dolan, R. J. (1996). Active representation of shape and spatial location in man. Cerebral Cortex, 6, 612-619.

Belger, A., Puce, A., Krystal, J. H., Gore, J. C., Goldman-Rakic, P. S., \& McCARTHY, G. (1998). Dissociation of mnemonic and perceptual processes during spatial and nonspatial working memory using fMRI. Human Brain Mapping, 6, 14-32.

Boynton, G. M., Engel, S. A., Glover, G. H., \& Heeger, D. J. (1996). Linear systems analysis of functional magnetic resonance imaging in human V1. Journal of Neuroscience, 16, 4207-4221.

Buckner, R. B., Bandettini, P. A., O'Craven, K. M., Savoy, R. L., Petersen, S. E., Raichle, M. E., \& Rosen, B. R. (1996). Detection of cortical activation during averaged single trials of a cognitive task using functional magnetic resonance imaging. Proceedings of the National Academy of Sciences, 93, 14878-14883.

Chafee, M. V., \& Goldman-Rakic, P. S. (1998). Matching patterns of activity in primate prefrontal area $8 \mathrm{a}$ and parietal area 7 ip neurons during a spatial working memory task. Journal of Neurophysiology, 79, 2919-2940.

Courtney, S. M., Petit, L., Maisog, J. M., Ungerleider, L. G., \& HAXBY, J. V. (1998). An area specialized for spatial working memory in human frontal cortex. Science, 279, 1347-1351.

Courtney, S. M., Ungerleider, L. G., KeIl, K., \& HaXby, J. (1996). Object and spatial visual working memory activate separate neural systems in human cortex. Cerebral Cortex, 6, 39-49.

Della Sala, S., Gray, C., Baddeley, A., Allamano, N., \& Wilson, L. (1999). Pattern span: A tool for unwelding visuo-spatial memory. Neuropsychologia, 37, 1189-1199.

D'Esposito, M., Aguirre, G. K., Zarahn, E., \& Ballard, D. (1998). Functional MRI studies of spatial and non-spatial working memory. Cognitive Brain Research, 7, 1-13.

D'Esposito, M., \& Postle, B. R. (1999). The dependence of span and delayed-response performance on prefrontal cortex. Neuropsychologia, 37, 1303-1315.

D'Esposito, M., Postle, B. R., Ballard, D., \& Lease, J. (1999). Maintenance versus manipulation of information held in working memory: An event-related fMRI study. Brain \& Cognition, 41, 66-86.

D'Esposito, M., Postle, B. R., Berger, J. S., \& TAich, A. M. (1999). Quantitative analysis of prefrontal and parietal cortical activity, as measured with event-related fMRI, during discrete components of delayed-response tasks. Society for Neuroscience Abstracts, 25, 1289.

D'Esposito, M., Postle, B. R., \& Rypma, B. (in press). Prefrontal cortical contributions to working memory: Evidence from event-related fMRI studies. Experimental Brain Research.

Fox, P. T., Mintun, M. A., Raichle, M. E., Miezin, F. M., Allman, J. M., \& VAN ESSEN, D. C. (1986). Mapping human visual cortex with positron emission tomography. Nature, 323, 806-809.

Fox, P. T., Mintun, M. A., Reiman, E. M., \& Raichle, M. E. (1988) Enhanced detection of focal brain responses using intersubject averaging and change-distribution analysis of subtracted PET images. Journal of Cerebral Blood Flow \& Metabolism, 8, 642-653.
Friston, K. J., Holmes, A. P., Poline, J.-B., Heather, J. D., \& FrackOWIAK, R. S. J. (1995). Analysis of fMRI time-series revisited. NeuroImage, 2, 45-53.

Friston, K. J., Holmes, A. P., \& Worsley, K. J. (1999). How many subjects constitute a study? NeuroImage, 10, 1-5.

Friston, K. J., Price, C. J., Fletcher, P., Moore, C., Frackowiak, R. S. J., \& Dolan, R. J. (1996). The trouble with cognitive subtraction. Neurolmage, 4, 97-104.

Funahashi, S., Bruce, C. J., \& Goldman-Rakic, P. S. (1990). Visuospatial coding in primate prefrontal neurons revealed by oculomotor paradigms. Journal of Neurophysiology, 63, 814-831.

Funahashi, S., Bruce, C. J., \& Goldman-Rakic, P. (1993). Dorsolateral prefrontal lesions and oculomotor delayed-response performance: Evidence for mnemonic "scotomas." Journal of Neuroscience, 13, 1479-1497.

FUSTER, J. M. (1997). The prefrontal cortex: Anatomy, physiology, and neuropsychology of the frontal lobe (3rd ed.). Philadelphia: LippincottRaven.

Gabrieli, J. D. E., Poldrack, R. A., \& Desmond, J. E. (1998). The role of left prefrontal cortex in language and memory. Proceedings of the National Academy of Sciences, 95, 906-913.

Goldman, P. S., \& Rosvold, H. E. (1970). Localization of function within the dorsolateral prefrontal cortex of the rhesus monkey. $E x$ perimental Neurology, 27, 291-304.

Goldman-RaKIC, P. S. (1987). Circuitry of the prefrontal cortex and the regulation of behavior by representational memory. In V. B. Mountcastle, F. Plum, \& S. R. Geiger (Eds.), Handbook of neunobiology (pp. 373-417). Bethesda, MD: American Physiological Society.

Gross, C. G. (1963). A comparison of the effects of partial and total lateral frontal lesions on test performance by monkeys. Journal of Comparative \& Physiological Psychology, 56, 41-47.

Haxby, J. V., Petit, L., Ungerleider, L. G., \& Courtney, S. M (2000). Distinguishing the functional roles of multiple regions in distributed neural systems for visual working memory. Neurolmage, 11 380-391.

Henson, R. N. A., Burgess, N., \& Frith, C. D. (2000). Recoding, storage, rehearsal and grouping in verbal short-term memory: An fMRI study. Neuropsychologia, 38, 426-440.

JoSEPhS, O., TURner, R., \& FrISTON, K. (1997). Event-related fMRI. Human Brain Mapping, 5, 243-248.

McCarthy, G., Puce, A., Constable, R. T., Krystal, J. H., Gore, J. C., \& Goldman-RAKIC, P. S. (1996). Activation of human prefrontal cortex during spatial and nonspatial working memory tasks measured by functional MRI. Cerebral Cortex, 6, 600-611.

Mishkin, M., \& MANNING, F. J. (1978). Non-spatial memory after selective prefrontal lesions in monkeys. Brain Research, 143, 313-323.

Nystrom, L. E., Braver, T. S., SabB, F. W., Delgado, M. R., Noll, D. C., \& Cohen, J. D. (2000). Working memory for letters, shapes and locations: fMRI evidence against stimulus-based regional organization of human prefrontal cortex. Neurolmage, 11, 424-446.

Oster, M. N., SNOW, M., MILler, E. K., \& CORKIN, S. (1997). fMRI activation during performance on object and spatial components of a working memory task. Society for Neuroscience Abstracts, 23, 2110.

Owen, A. M., Evans, A. C., \& Petrides, M. (1996). Evidence for a two-stage model of spatial working memory processing within the lateral frontal cortex: A positron emission tomography study. Cerebral Cortex, 6, 31-38.

Owen, A. M., Herrod, N. J., Menon, D. K., Clark, J. C., Downey, S. P. M. J., Carpenter, T. A., Minhas, P. S., Turkheimer, F. E., Williams, E. J., Robbins, T. W., Sahakian, B. J., Petrides, M., \& Pickard, J. D. (1999). Redefining the functional organization of working memory processes within human lateral prefrontal cortex. European Journal of Neuroscience, 11, 567-574.

OWen, A. M., Iddon, J. L., Hodges, J. R., Summers, B. A., \& RobBins, T. W. (1997). Spatial and non-spatial working memory at different stages of Parkinson's disease. Neuropsychologia, 35, 519-532.

Owen, A. M., Stern, C. E., Look, R. B., Tracey, I., Rosen, B. R., \& Petrides, M. (1998). Functional organization of spatial and nonspa- 
tial working memory processing within the human lateral frontal cortex. Proceedings of the National Academy of Sciences, 95, 7721-7726.

Passingham, R. (1975). Delayed matching after selective prefrontal lesions in monkeys. Brain Research, 92, 89-102.

Paulesu, E., Frith, C. D., \& Frackowiak, R. S. J. (1993). The neural correlates of the verbal component of working memory. Nature, $\mathbf{3 6 2}$, 342-345.

Petrides, M. (1994). Frontal lobes and working memory: Evidence from investigations of the effects of cortical excisions in nonhuman primates. In F. Boller \& J. Grafman (Eds.), Handbook of neuropsychology (pp. 59-82). Amsterdam: Elsevier.

Posner, M. I., Petersen, S. E., Fox, P. T., \& Raichle, M. E. (1988). Localization of cognitive operations in the human brain. Science, 240, 1627-1632.

Postle, B. R., Berger, J. S., \& D’Esposito, M. (1999). Functional neuroanatomical double dissociation of mnemonic and executive control processes contributing to working memory performance. Proceedings of the National Academy of Sciences, 96, 12959-12964.

Postle, B. R., \& D'Esposito, M. (1999). "What"-then-"where" in visual working memory: An event-related fMRI study. Journal of Cognitive Neuroscience, 11, 585-597.

Postle, B. R., Jonides, J., Smith, E., Corkin, S., \& Growdon, J. H. (1997). Spatial, but not object, delayed response is impaired in early Parkinson's disease. Neuropsychology, 11, 1-9.

Postle, B. R., Stern, C. E., Rosen, B. R., \& Corkin, S. (2000). An fMRI investigation of cortical contributions to spatial and nonspatial visual working memory. Neurolmage, 11, 409-423.

Postle, B. R., Zarahn, E., \& D'Esposito, M. (2000). Using eventrelated $\mathrm{fMRI}$ to assess delay-period activity during performance of spatial and nonspatial working memory tasks. Brain Research Protocols, 5, 57-66.

Rainer, G., AsaAd, W. F., \& Miller, E. K. (1998). Memory fields of neurons in the primate prefrontal cortex. Proceedings of the National Academy of Sciences, 95, 15008-15013.

RaO, S. C., Rainer, G., \& Miller, E. K. (1997). Integration of what and where in the primate prefrontal cortex. Science, 276, 821-824.

Richter, W., Ugurbil, K., Georgopoulos, A., \& Kim, S.-G. (1997). Time-resolved fMRI of mental rotation. NeuroReport, 8, 3697-3702.

Rushworth, M. F. S., Nixon, P. D., Eacott, M. J., \& Passingham, R. E. (1997). Ventral prefrontal cortex is not essential for working memory. Journal of Neuroscience, 17, 4829-4838.

Sarter, M., Berntson, G. G., \& CACioppo, J. T. (1996). Brain imaging and cognitive neuroscience: Toward strong inference in attributing function to structure. American Psychologist, 51, 13-21.

SMITH, E. E., \& JoNIDES, J. (1999). Storage and executive processes of the frontal lobes. Science, 283, 1657-1661.

Smith, E. E., Jonides, J., Koeppe, R. A., Awh, E., Schumacher, E. H., \& Minoshima, S. (1995). Spatial vs. object working memory: PET investigations. Journal of Cognitive Neuroscience, 7, 337-356.
Smith, E. E., Jonides, J., Marshuetz, C., \& Koeppe, R. A. (1998) Components of verbal working memory: Evidence from neuroimaging. Proceedings of the National Academy of Sciences, 95, 876-882.

Tresch, M. C., Sinnamon, H. M., \& Seamon, J. G. (1993). Double dissociation of spatial and object visual memory: Evidence from selective interference in intact human subjects. Neuropsychologia, 31, 211-219.

Ungerleider, L. G., Courtney, S. M., \& Haxby, J. V. (1998), A neural system for visual working memory. Proceedings of the $\mathrm{Na}$ tional Academy of Sciences, 95, 883-890.

UNGerleider, L. G., \& HAXBY, J. (1994). "What" and "where" in the human brain. Current Opinion in Neurobiology, 4, 157-165.

UNGERLEIDER, L. G., \& MishKIN, M. (1982). Two cortical visual systems. In D. J. Ingle, M. A. Goodale, \& R. J. W. Mansfield (Eds.), Analysis of visual behavior (pp. 549-586). Cambridge, MA: MIT Press.

WAGNER, A. D. (1999). Working memory contributions to human learning and remembering. Neuron, 22, 19-22.

Wilson, F. A. W., O'SCal.aidhe, S. P., \& Goldman-Rakic, P. S. (1993), Dissociation of object and spatial processing domains in primate prefrontal cortex. Science, 260, 1955-1958.

WooDs, R. P. (1996). Modeling for intergroup comparisons of imaging data. NeuroImage, 4, S84-S94.

WorSLEY, K. J., \& Friston, K. J. (1995). Analysis of fMRI time-series revisited-Again. Neurolmage, 2, 173-182.

Zarahn, E., Aguirre, G. K., \& D'Esposito, M. (1997a). Empirical analyses of BOLD $f$ MRI statistics: I. Spatially unsmoothed data collected under null-hypothesis conditions. Neurolmage, 5, 179-197.

Zarahn, E., Aguirre, G. K., \& D'Esposito, M. (1997b). A trial-based experimental design for $\mathrm{fMRI}$. Neurolmage, 6, 122-138.

Zarahn, E., AGUiRre, G. K., \& D'Esposito, M. (1999). Temporal isolation of the neural correlates of spatial mnemonic processing with functional MRI. Cognitive Brain Research, 7, 255-268.

\section{NOTE}

1. Strictly speaking, our event-related method yields uncontaminated estimates of delay-period activity only (Zarahn et al., 1997b). Our estimates of target- and probe-related activity may reflect contributions from the earliest and latest portions of the delay period, respectively. Because, however, fMRI activity evoked by the presentation of a stimulus typically far exceeds the fMRI activity evoked by delay-period processes (D'Esposito, Postle, Berger, \& Taich, 1999), we feel secure attributing target- or probe-related estimates of fMRI signal to the activity evoked by those two trial components.

(Manuscript received December 1, 1999; revision accepted for publication April 1, 2000.) 